\title{
Employment status and work ability in long-term young adult cancer
}

\section{survivors}

\author{
Alv A. Dahl' ${ }^{1,2}$, Sophie D. Fosså ${ }^{1}$, Hanne C. Lie ${ }^{1,3,4}$, Jon Håvard Loge ${ }^{3,5}$, \\ Kristin Valborg Reinertsen ${ }^{1,6}$, Ellen Ruud ${ }^{2,4}$, Cecilie Essholt Kiserud ${ }^{1}$
}

${ }^{1}$ National Advisory Unit on Late Effects after Cancer Treatment, Oslo University Hospital, Radiumhospitalet, 0424 Oslo, Norway.

${ }^{2}$ Faculty of Medicine, University of Oslo, 0316 Oslo, Norway.

${ }^{3}$ Department of Behavioural Sciences in Medicine, University of Oslo, Norway.

${ }^{4}$ Department of Paediatric Medicine, Oslo University Hospital, Rikshospitalet, 0029 Oslo, Norway.

${ }^{5}$ Regional Advisory Unit on Palliative Care, Oslo University Hospital, 0310 Oslo, Norway.

${ }^{6}$ Department of Oncology, Oslo University Hospital, Ullevål Hospital, 0406 Oslo, Norway.

E-mail addresses: a.a.dahl@ibv.uio.no; sopfos@ous-hf.no; h.c.lie@medisin.uio.no;

j.h.loge@medisin.uio.no; KVR@ous-hf.no; elruud@ous-hf.no; CKK@ous-hf.no

\section{Corresponding author:}

Alv A. Dahl, MD, PhD

Oslo University Hospital, Radiumhospitalet, P.O. Box 4953 Nydalen, 0424 Oslo, Norway.

Phone: 004722934909 Fax 004722934553 E-mail: a.a.dahl@ibv.uio.no

Running head: Employment status and work ability in YA cancer survivors

Key words: work status - work ability - treatment intensity - long-term adverse effects 


\section{Abstract}

Purpose: In young adult cancer survivors (YACSs) to explore the rate of being non-employed and having reduced work ability, and to identify factors associated with these two outcomes. Methods: All Norwegian YACSs $(\mathrm{N}=3,558)$ diagnosed at age 19-39 years and treated between 1985-2009 for breast or colo-rectal cancer, leukemia, non-Hodgkin's lymphoma, or melanoma and alive in 2015 were mailed a questionnaire covering adverse outcomes, comorbidities, work and psychosocial variables. The response rate was $42 \%(\mathrm{~N}=1,488)$. A minimal treatment reference group consisted of 198 YACSs with non-metastatic melanoma, and 1,000 YACSs with the other cancers formed the local, systemic and systemic plus other treatment groups. Work status was compared to normative data.

Results: The sample included 63\% females. Median age at survey was 49 years (range $27-$ 65), and median time since first cancer diagnosis was 16 years (range 6-31). At survey, 25\% (95\%CI 22-27\%) of YACSs were not employed, and work ability reduction was reported by $38 \%(95 \%$ CI $35-41 \%)$. The rate of being non-employed was the same in YACSs as in normative data. More female YACSs held disability pension compared to normative data. In multivariate analyses increased number of adverse effects, comorbid cardiovascular diseases, lower basic education, reduced level of self-rated health, and increased level of depression were significantly associated with both not being employed and reduced work ability.

Conclusions: This long-term questionnaire survey found that YACSs had the same employment rates as among normative controls. Among YACSs 38\% reported reduced work ability, but here normative data are lacking. 


\section{Introduction}

Young adulthood (19 to 39 years) is a phase of life focused on finishing education, career development, establishment of paired civil status, and eventual parenthood. A diagnosis of cancer during these years may interfere significantly with these tasks. As Norwegian workers can be employed until they are 67 years, young adult cancer survivors (YACSs) putatively have many years of work life ahead when returning to work after treatment cessation or when they start working after finishing their education. However, a recent review providing a comprehensive analysis of what is known about YACSs and employment, reported few studies on their long-term employment status and their work ability. ${ }^{1}$

Concerning work status, official statistics often separate persons who are employed from those who are non-employed and supported economically various kinds of insurance. However, non-employed person can still retain a subjective work ability useful for performing non-paid tasks for their families, organizations, or for society. ${ }^{2,3}$ Another aspect hardly covered in the review was the relation between long-term adverse effects (AEs) and employment. AEs are strongly related to treatment modalities. ${ }^{4,5}$

The CAYAC is a national, population-based, Norwegian cross-sectional questionnaire study of childhood cancer survivors and YACSs at long-term since diagnosis, focusing primarily on their perceived needs of information and follow-up care. The CAYAC also collected work-related data used in the current sub-study of YACSs for two objectives: 1) To examine the prevalence of being non-employed compared to normative data, to compare being non-employed with employed, and to identify variables significantly associated with non-employed work status. 2) To examine the prevalence of low current work ability, to compare those with low and high work ability, and to identify variables significantly associated with low work ability. 


\section{Patients and Methods}

Since 1953 The Cancer Registry of Norway has systematically collected notifications on all new cancer cases in the Norwegian population. The Cancer Registry contains data related to initial diagnosis, primary treatment, and survival of cancer patients. Included in the CAYAC study were all childhood cancer incidences diagnosed but CNS tumors aged from 0 to 18 years and incidences aged 19 to 39 years first diagnosed from 1985 to 2009 and alive at September 2, 2015. with one of five pre-selected first lifetime cancers. Only the latter agegroup was included in the current sub-study, which included cancer types common during young adult years, with good prognosis, and not included in other ongoing studies at our research unit for late effects (https://www.ous-research.no/longterm/).

The initial YACSs sample included breast cancer (stage I-III, N=1,257), malignant melanoma $(\mathrm{N}=2,902)$, colo-rectal cancer $(\mathrm{N}=380)$, leukemia $(\mathrm{N}=338)$, or non-Hodgkin's lymphoma $(\mathrm{N}=623)$. Due to their large number only a random sample of $33 \%$ melanomas was included $(\mathrm{N}=960)$. This resulted in a total sample of 3,558 YACSs.

In September 2015, this sample was mailed a questionnaire covered information and follow-up care needs, current mental and physical health, lifestyle, and work issues, using available scales with good psychometric properties. Non-responder got a reminder five months later. Among those invited, 1,488 YACSs (42\%) responded: 597 with breast cancer, 155 with colo-rectal cancer, 253 with lymphoma, 157 with leukemia, and 326 with melanoma. Among respondents, we excluded YACSs who did not report data on oncological or who had a new cancer diagnosis within two years before the survey $(\mathrm{N}=162)$. Thus, 1,326 YACS were eligible for this sub-study. 


\section{Primary outcome variables}

Current employment status was dichotomized into "employed" (full- and part-time work and on sick leave) versus "non-employed" (work assessment allowance, disability pension, or others like students or homemakers). Current work ability compared to the lifetime best on a 10-point VAS scale from zero ("Currently not able to do work") to 10 ("Work ability as previous life-time best") from the Work Ability Index (WAI) instrument. ${ }^{2,3}$ The scorings were dichotomized into high (score 8-10) and low (score 0-7) work ability. ${ }^{6}$ This one-item approach has been validated. ${ }^{7}$

\section{Cancer-related variables}

Information on cancer types and stages was retrieved from the Cancer Registry, while data on cancer treatment and relapses were self-reported. In order to identify a reference treatment group characterized by minimal surgery, we excluded 128 YACSs from the melanoma group with metastases, new cancer, relapse, or extensive treatments, leaving 198 YACSs treated with MS. The local treatment group consisted of YACSs who had major surgery and/or radiotherapy only $(\mathrm{N}=206)$, the systemic treatment group only received chemotherapy and/or endocrine treatment $(\mathrm{N}=194)$, while the systemic and other treatment group, also had surgery and/or radiotherapy $(\mathrm{N}=600)$. The total sample of this study thereby consisted of 1,198 YACSs.

Long-term adverse effects (AEs) were self-reported (yes/no) according to personal experience. A list of relevant AEs were compiled based on existing literature and in consultation with experienced clinicians who work within the relevant diagnostic groups. ${ }^{4,5}$ We included 13 relevant AEs: hormonal changes, reduced fertility, lung problems, dental health problems, cognitive problems, hearing problems, muscular cramps, nerve pains, numbness in hands/feet, sexual problems, osteoporosis, lymphedema, and radiation injuries. The number of reported AEs was summarized as a continuous variable (Total AEs). Since 
chronic fatigue, anxiety, and depression were rated by scales, these AEs were not include among AEs.

\section{Scales}

The current study included four scales: The Fatigue Questionnaire ${ }^{8,9}$, Hospital Anxiety and Depression Scale, anxiety subscale ${ }^{10}$, The Patient Health Questionnaire- ${ }^{11}$, and the self-rated health items from The European Organization for Research and Treatment of Cancer (EORTC) QLQ-C30 ${ }^{12}$. Details are described in Table 1.

\section{Questions}

Current paired relation was categorized as present or absent. Level of basic education was dichotomized into low ( $\leq 12$ years) and high ( $>12$ years). Cardiovascular diseases included a diagnosis at any time given by a doctor of myocardial infarction, angina pectoris, heart failure, stroke, diabetes, or hypertension. Correspondingly, musculo-skeletal diseases included a diagnosis of arthrosis, rheumatic diseases, or other chronic diseases in muscles and/or joints. Mental disorders included depression or other mental problems leading to helpseeking. Obesity concerned a body mass index $\geq 30$, and smoking identified current daily smoking of any number of cigarettes, at survey.

\section{Normative data}

Relevant work-related norm data were retrieved from the home pages of Statistics Norway (https://www.ssb.no/en/) and the Norwegian Labor and Welfare Service

(https://www.nav.no/en/). Norwegian official registries are collected by various agencies of the government, and the fact that all individuals living in Norway have a unique personal number can be used for cross-checking across registries.

\section{Statistical analyses}

Between-group comparisons of continuous variables were performed with independent 
sample t-tests, and with skewed distributions non-parametric tests were used. Between-group comparisons of categorical variables were performed with chi-square tests. The internal consistencies of scales were examined with Cronbach's coefficient alpha, which were 0.83 or higher for all instruments.

Due to the majority of female YACSs in our sample, we adjusted relevant between-group comparisons for sex using multivariable linear and logistic regression analyses. Associations between independent variables and non-employed status (employed as reference) and low current work ability (high as reference) were examined with univariate and multivariable logistic regression analyses. The strength of the associations was given as odds ratios (ORs) with $95 \%$ confidence intervals as appropriate $(95 \% \mathrm{CI})$. Due to multicollinearity with work ability, employment status was not included in the multivariable analysis of work ability.

The significant $p$-value was set as $<0.05$, and all tests were two-sided. The software applied was IBM SPSS Statistics version 24 for PC (IBM Corporation, Armonk, New York, USA).

\section{Ethics}

The project was approved by the Regional Committee for Medical and Health Research Ethics of South-East Norway (\#2016/953). All participants gave informed consents.

\section{Results}

The final sample consisted of $323(27 \%)$ males and 875 females (63\%) with median age 35 years (range 19-39) at first cancer diagnosis and 49 years (range 27-65) at survey. Median time since first diagnosis was 16 years (range 6-31). Cancer and treatment data are displayed in Table 2.

\section{Employment status}


Among 1,189 YACSs who reported on employment status, 897 (75\%, 95\% CI 73-78\%) were employed and 292 (25\%, 95\% CI 22-27\%) were non-employed. Among male YACSs 83\% were employed compared to $81 \%$ among males aged 25-66 years in the Norwegian population. For females, the corresponding numbers were $73 \%$ and $76 \%$, respectively. Among YACSs, $10 \%$ of the males and $19 \%$ of females held disability pension, while the corresponding numbers for those aged $25-65$ years in the general population were $11 \%$ and $13 \%$, respectively.

YACSs in the non-employed group had significantly higher mean age at survey and longer mean time since first cancer diagnosis than those employed. Compared to employed YACSs, a significantly smaller proportion of YACSs in the non-employed group had received treatment with MS, while significantly more was treated with systemic and other treatments $(\mathrm{ST}+)$ compared to the employed YACSs (Table 1). YACSs in the non-employed group also reported a significantly higher mean number of AEs, and a significantly higher proportion of them were females and YACSs with lower level of basic education compared to those being employed. Those in the not employed group also reported significantly higher rates of comorbid cardiovascular, musculo-skeletal and mental diseases, and had higher prevalences of obesity and daily smoking. Higher mean levels of total fatigue, anxiety, and depression, and lower level of general health were also characteristic for the non-employed group (Table 1). In the multivariate analysis, the following variables remained significantly associated with YACSs being non-employed: longer time since first cancer diagnosis, increased mean number of AEs, being female, low basic education, comorbid cardio-vascular disease, decreased general health, and increased level of depression. (Table 2).

\section{Work ability}

Among the 1140 YACSs reporting on work ability, 706 (62\%, 95\% CI 59-65\%) had high, while $434(38 \%, 95 \%$ CI 35-41\%) had low current work ability $(\mathrm{N}=1,140)$. The mean work 
ability scores were 9.1 (SD 4.5) in the high and 4.5 (SD 2.3) $(\mathrm{p}<0.001)$ in the low work ability group. The work ability score in the total sample was 7.4 (SD 2.7), 8.3 (SD 1.8) among those employed and 3.9 (SD1.9) $(\mathrm{p}<0.001)$ among those not employed.

YACSs with low work ability had significantly higher mean age at first cancer diagnosis than those with high work ability. Significantly fewer YACSs with melanoma and significantly more with breast cancer and non-Hodgkin lymphomas had low work ability. YACSs with low work ability also had less often received MS and LT, but significantly more often $\mathrm{ST}+$, and had more relapses and more than one cancer compared with the high work ability group (Table 3). The mean number of AEs was significantly higher among those in the low work ability group, which also had a significantly higher number of females and YACSs with lower level of basic education compared to the group with high work ability. Those in the low work ability group also had significantly higher rate of comorbid cardiovascular, musculo-skeletal and mental diseases, and higher rates of current obesity and daily smoking. They also reported significantly higher mean levels of total fatigue, anxiety, and depression, and lower level of general health. Also in that group a significantly lower proportion held fulltime jobs, while higher proportions held part-time jobs, were on sick leave, work assessment allowance, and on disability pension (Table 3 ).

In the multivariate analysis the following variables remained significantly associated with YACS having low current work ability: ST and ST+ treatment, increased mean number of AEs, comorbid cardiovascular disease, low basic education, decreased level of general health, and increased levels of total fatigue and depression (Table 4).

\section{Discussion}

At survey, 25\% of YACSs were non-employed at a median age of 49 years and 16 years since their first cancer diagnosis, In multivariate analysis non-employed status was significantly associated with being female, longer time since first cancer diagnosis, increasing number of 
AEs, lower basic education, comorbid cardiovascular disease, decreased level of general health and increased levels of depression. Type of cancer, treatment and cancer relapse were not associated with current work status.

At survey, 38\% of YACSs reported low current work ability, which in multivariate analysis was associated with the same variables as being non-employed except for being female and longer interval since first diagnosis. In addition, having been exposed to systemic treatment (ST and ST+) and increased level of total fatigue significantly decreased work ability.

In spite of the conceptual differences between employment and work ability statuses, their multivariate analyses had low basic education, increased mean number of AEs, comorbid cardio-vascular disease, decreased general health, and increased level of depression in common. These variables therefore are of obvious relevance for YACSs work life situation at long-term. While basic education belongs to the past, the other four variables are currently relevant, and should be in focus by the health care providers responsible for the follow-up of YACSs.

Interestingly, being female YACSs was a significant factor concerning nonemployment status, but not for low work ability status in multivariate analyses. One explanation could be that a proportion of female YACSs has too low work ability for official work life, but still do a lot of unpaid work within family, charity, and as volunteers. Increased prevalence of disability pension among female YACSs compared to the norm (19\% versus $11 \%)$ could also be part of the explanation for this finding.

Even though older age of YACS at survey was significantly associated with being unemployed in univariate analysis, age was surprisingly not significantly associated with any of the work outcomes in the multivariate analyses. This finding could be explained by the fact that the YACSs were young with a median age of 49 years at survey. The full impact of age 
on work outcomes still was not yet reached by our sample.

The employment rate of YACSs of both sexes were similar to those found in the general population. This finding is in contrast to studies that have reported higher rates of non-employment in cancer survivors. ${ }^{10}$ One explanation may be the very low rates of nonemployment that Norway have had for several decades compared to most our countries. Being employed or not is dependent on national legal and economic regulations concerning the labor market, prevalence of unemployment among young adults, and criteria for getting social support. The rate of disability pension among male YACSs was similar to the population and significantly lower than for female YACSs, who had a higher rate than the population. This finding is in line with results from previous Scandinavian studies. ${ }^{11}$

While employment status is categorized objectively, current work ability is a subjective measure compared to lifetime best. The advantage of assessing this outcome is its independence from employment status, making it useful for YACSs who are non-employed but still able to do useful work. One problem with current work ability is the comparison with "lifetime best", which could be years ago indicating problems of recall and eventual response shift. ${ }^{12}$

A systematic review of work ability in cancer survivors found low work ability to be significantly associated with increased fatigue, anxiety, and depression as observed in our study. ${ }^{13}$ A Nordic study also demonstrated a significant association between low work ability and comorbidities as also found by us. ${ }^{14}$ There is a lack of population-based normative data concerning current work ability, which represents a weakness of studies of that work outcome.

We defined four treatment modalities with increasing treatment intensity with minimal surgery as reference. Heavier treatment burden was significantly associated with both nonemployment and low current work ability in univariate analyses. In contrast, minimal surgery 
was negatively associated with poor work outcomes. More intensive treatments were significantly associated with low work ability in the multivariate analysis. Treatment intensity thus seem to have a long-lasting effect on work outcomes.

However, treatment that is more intensive also implies more AEs, we found that the negative effects of AEs on work performance were statistically stronger than those associated with cancer types and treatment intensity. This finding underlines the clinical relevance of checking unemployed YACSs for AEs at follow-up visits. Note that cardiovascular diseases, chronic fatigue, and mental distress were omitted from our list of AEs, since other variables and instruments covered them. If these variables had been included among the AEs, the impact of AEs on work outcomes would have been even stronger.

Lifestyle factors, like obesity and daily smoking, could have been established before the primary cancer diagnosis or later on. Even though not significant in multivariate analyses, they showed statistically significant associations with both work outcomes in the univariate models. Therefore, modifications of unhealthy lifestyle could be relevant for improvement of current work ability and work status, and additionally have protective effects concerning relapses and second cancers.

In their recent systematic review of 23 papers concerning YACSs and work, Stone et al. ${ }^{1}$ did not specify comorbidity, which was an important factor negatively associated with poorer work outcomes in our study, just like low level of education mentioned in their review. Like them, we observed that aspects of mental distress (anxiety and depression) were significantly associated with poorer work outcomes. Our findings also supported their conclusion that: "the related studies found that survivors become equal to healthy controls overall in achieving a successful career" although we only examined employment rates.

\section{Strengths and limitations}

Patient identification by the CRN precluded any selection bias concerning the YACSs 
addressed by us. Use of established instruments for key variables is considered a major strength. The same could be said for our use of two different work outcomes, one categorical and objective and one dimensional and subjective. Our response rate was $42 \%$, which is quite common in population-based questionnaire surveys without any rewards for responding. The reliance of self-report of treatment is an obvious limitation. Another is that we do not know if cancer was the specific reason for non-employment or low work ability. The cross-sectional design of our sub-study precludes drawing causal conclusions. Another limitation concerns our lack of data on family income, which could be relevant for work status of YACSs.

\section{Conclusion}

In YACSs treated at a median age of 35 years and surveyed at median age of 49 years, $25 \%$ were not in paid work and 38\% had reduced current work ability. Increased mean number of AEs, comorbid cardiovascular diseases, reduced level of self-rated health, and increased level of depression were significantly associated with both these outcome variables. In order to keep YACSs employed or eventually to improve their work ability these factors should be focused on by the health care providers responsible for the follow-up of YACSs.

\section{Author Disclosure Statement}

No competing financial interest exist.

\section{Funding}

The project has received funding from The Norwegian Research Council (grant \#218312) and the Norwegian Cancer Association (grant \# 45480), and from the Legacies of the Norwegian Radium Hospital (grant \# 335007).

\section{References}


1. Stone DS, Ganz PA, Pavlish C, Robbins WA. Young adult cancer survivors and work: a systematic review. J Cancer Surviv 2017;11(6):765-81.

2. Tuomi K, Ilmarinen J, Jakhola A, Katajarinne L, Tulkki A. Work Ability Index. 2nd edition. Helsinki: Finnish Institute of Occupational Health, 2006.

3. van den Berg TIJ, Elders LAM, de Zwart BCH, Burdorf A. The effects if work-related and individual factors on the Work Ability Index: a systematic review. Occup Environ Med 2009;66(4):211-20.

4. Ganz PA. Survivorship: Adult cancer survivors. Prim Care Clin Office Pract 2009;36(4): 721-41.

5. Kiserud CE, Dahl AA, Fosså SD. Cancer survivorship in adults. Recent Results Cancer Res 2018;210:123-143.

6. Dahl S, Cvancarova M, Dahl AA, et al. Work ability inprostate cancer survivors after radical prostatectomy. Scan J Urol 2016;50(2):116-22.

7. Ahlstrom L, Grimby-Ekman A, Hagberg M, Dellve L. The work ability index and singleitem question: associations with sick leave, symptoms, and health - a prospective study of women on long-term sick leave. Scand J Work Environ Health 2010;36(5):404-12.

8. Chalder T, Berelowitz G, Pawlikowska T, et al. Development of a fatigue scale. J Psychosom Res. 1993;37(2):147-53.

9. Loge JH, Ekeberg O, Kaasa S. Fatigue in the general Norwegian population: normative data and associations. J Psychosom Res 1998;45(1):53-65.

10. Bjelland I, Dahl AA, Haug TT, Neckelmann D. The validity of the Hospital Anxiety and Depression Scale. An updated literature review. J Psychosom Res 2002;52(2):69-77.

11. Kroenke K, Spitzer RL, Williams JBW. The PHQ-9: Validity of a brief depression severity measure. J Intern Med 2001;16(9):606-13. 
12. Aaronson NK, Ahmedzai S, Bergman B, et al. The European Organization for Research and Treatment of Cancer QLQ-C30: a quality-of-life instrument for use in international clinical trials in oncology. J Natl Cancer Inst. 1993;85(5):365-76.

13. de Boer AG, Taskila T, Ojajärvi A, et al. Cancer survivors and unemployment: a metaanalysis and meta-regression. JAMA 2009;301(7):753-62.

14. Carlsen K, Oksbjerg Dalton S, Frederiksen K, et al. Cancer_and the risk for taking early retirement pension: a Danish cohort study. Scand J Public Health 2008;36(2):117-25.

15. von Bonsdorff ME, Rantanen T, Törmäkangas T, et al. Midlife work ability and mobility limitation in old age among non-disability and disability retirees - a prospective study. BMC Public Health 2016;16:154

16. Mehnert A, Barth J, Gaspar M, et al. Predictors of early retirement after cancer rehabilitation - a longitudinal study. Eur J Cancer Care 2017;26(5) doi. 10.1111/ecc 12528. 
Table 1. Information about scales used in this study.

\begin{tabular}{|l|l|l|l|}
\hline \multicolumn{1}{|c|}{ Scale } & \multicolumn{1}{|c|}{ Content/Sub-scales } & \multicolumn{1}{c|}{ Scoring } & \multicolumn{1}{c|}{ Sum score } \\
\hline $\begin{array}{l}\text { The Fatigue } \\
\text { Questionnaire (FQ) }\end{array}$ & $\begin{array}{l}\text { Mental (four items) } \\
\text { Physical (seven items) } \\
\text { Total (11 items) }\end{array}$ & $\begin{array}{l}\text { (less than before/ } \\
\text { not at all) to 3 (very } \\
\text { much/ worse) }\end{array}$ & $\begin{array}{l}\text { Mental 0 -12 } \\
\text { Physical 0 -21 } \\
\text { Total 0 - 33 }\end{array}$ \\
\hline $\begin{array}{l}\text { Hospital Anxiety and } \\
\text { Depression Scale } \\
\text { (HADS) }\end{array}$ & Anxiety (seven items) & $\begin{array}{l}0 \text { (not present) to 3 } \\
\text { (highly present) }\end{array}$ & Anxiety 0 - 21 \\
\hline $\begin{array}{l}\text { The Patient Health } \\
\text { Questionnaire-9 } \\
\text { (PHQ-9) }\end{array}$ & $\begin{array}{l}\text { Depression (nine } \\
\text { items) }\end{array}$ & $\begin{array}{l}0 \text { (not at all) to 3 } \\
\text { (nearly every day) }\end{array}$ & Depression 0 - 27 \\
\hline $\begin{array}{l}\text { The European } \\
\text { Organization for } \\
\text { Research and } \\
\text { Treatment of Cancer } \\
\text { (EORTC) QLQ-C30 }\end{array}$ & $\begin{array}{l}\text { Self-rated general } \\
\text { health (one item) }\end{array}$ & $\begin{array}{l}1 \text { (very poor) to 7 } \\
\text { (excellent) } \\
\text { converted to 0 to } \\
100\end{array}$ & $\begin{array}{l}\text { General health 0 - } \\
100\end{array}$ \\
\hline
\end{tabular}


Table 2. Characteristics of employed and non-employed young adult cancer survivors at survey.

\begin{tabular}{|c|c|c|c|c|}
\hline Variables & $\begin{array}{c}\text { Employed } \\
(\mathrm{N}=\mathbf{8 9 7})\end{array}$ & $\begin{array}{c}\text { Non- } \\
\text { employed } \\
(\mathrm{N}=\mathbf{2 9 2})\end{array}$ & p-value & $\begin{array}{c}\text { Total } \\
(\mathrm{N}=1189)\end{array}$ \\
\hline Age at first diagnosis, mean (SD) & $33.2(5.7)$ & $32.9(5.1)$ & $0.69 \#$ & $33.0(5.3)$ \\
\hline Age at survey, mean (SD) & $49.3(7.3)$ & $51.1(9.0)$ & 0.001\# & $49.7(7.8)$ \\
\hline Time since diagnosis, mean (SD) & $15.9(6.7)$ & $17.3(6.9)$ & $<\mathbf{0 . 0 0 \#}$ & $16.8(6.8)$ \\
\hline Types of cancer, $N(\%)$ & & & 0.06 & \\
\hline Melanomas & $164(18)$ & $34(12)$ & 0.008 & 198 (17) \\
\hline Breast & $369(41)$ & $121(41)$ & 0.95 & $490(41)$ \\
\hline Colo-rectal & $109(12)$ & 39 (13) & 0.61 & $148(12)$ \\
\hline Non-Hodgkin lymphomas & $154(17)$ & $65(22)$ & 0.06 & 219 (19) \\
\hline Leukemias & $102(11)$ & $33(11)$ & 1.00 & $135(11)$ \\
\hline Treatment groups, $N(\%)$ & & & 0.02 & \\
\hline Minimal surgery & $164(18)$ & $34(11)$ & 0.008 & 198 \\
\hline Local treatment & $161(18)$ & $44(15)$ & 0.28 & $205(17)$ \\
\hline Systemic treatment only & 140 & $52(18)$ & 0.41 & $192(16)$ \\
\hline Systemic + others & $433(48)$ & $162(56)$ & 0.04 & $595(50)$ \\
\hline Relapse, N (\%) & $106(12)$ & $44(15)$ & 0.12 & $150(13)$ \\
\hline $\begin{array}{l}\text { Metastases ever (breast and colo- } \\
\text { rectal cancers) N (\%) }(\mathbf{N}=\mathbf{6 3 8})\end{array}$ & $266(42)$ & 90 (14) & $<0.001$ & $356(56)$ \\
\hline Number of cancers, $N(\%)$ & & & 0.17 & \\
\hline One cancer only & $834(93)$ & $264(90)$ & & $1098(92)$ \\
\hline Two or more cancers & $63(7)$ & $28(10)$ & & $91(2)$ \\
\hline $\begin{array}{l}\text { Number of late adverse effects, } \\
\text { mean (SD) }\end{array}$ & $1.8(2.1)$ & $3.0(2.7)$ & $<0.001 * \#$ & $2.1(2.3)$ \\
\hline $\operatorname{Sex}, N(\%)$ & & & $<0.001$ & \\
\hline
\end{tabular}




\begin{tabular}{|c|c|c|c|c|}
\hline Females & $631(70)$ & $236(81)$ & & $867(73)$ \\
\hline Males & $266(30)$ & 56 (19) & & $322(27)$ \\
\hline In paired relationship, $\mathrm{N}(\%)$ & 709 (79) & $217(74)$ & 0.09 & $926(78)$ \\
\hline Level of basic education, $N(\%)$ & & & $<0.001 \#$ & \\
\hline $\operatorname{High}(>12$ years $)$ & $576(64)$ & $122(42)$ & & $698(59)$ \\
\hline Low $(\leq 12$ years $)$ & $319(36)$ & $170(58)$ & & $489(41)$ \\
\hline Work status, $N(\%)$ & & & NA & \\
\hline Full time job & $689(77)$ & $0(0)$ & & $689(58)$ \\
\hline Part time job & $182(20)$ & $0(0)$ & & $182(15) 24$ \\
\hline On sick-leave & $24(3)$ & $0(0)$ & & (2) 198 \\
\hline Disability pension & $0(0)$ & $198(68)$ & & (17) 41 (3) \\
\hline Work assessment allowance & $0(0)$ & $41(14)$ & & $55(5)$ \\
\hline Other statuses & $2(0)$ & $53(18)$ & & \\
\hline Work ability index, mean (SD) & $8.3(1.8)$ & $3.9(2.9)$ & $<0.001 \#$ & $7.4(2.7)$ \\
\hline \multicolumn{5}{|l|}{ Comorbidities, $N(\%)$} \\
\hline Cardiovascular diseases & $199(22)$ & $126(43)$ & $<0.001 \#$ & $325(27)$ \\
\hline Musculo-skeletal diseases & $432(48)$ & $191(65)$ & $<0.001 \#$ & $623(52)$ \\
\hline Mental disorders & $213(24)$ & $118(40)$ & $<\mathbf{0 . 0 0 1 \#}$ & $331(28)$ \\
\hline General health, mean (SD) & $77.7(20.6)$ & $55.3(24.6)$ & $<0.001 \#$ & $72.3(22.6)$ \\
\hline Total fatigue, mean (SD) & $12.3(4.2)$ & $16.3(6.3)$ & $<0.001 \#$ & $13.2(5.1)$ \\
\hline Anxiety, mean (SD) & $4.2(3.5)$ & $6.1(4.2)$ & $<0.001 * \#$ & $4.7(3.7)$ \\
\hline Depression, mean (SD) & $4.4(4.1)$ & $8.3(5.3)$ & $<0.001 * \#$ & $5.3(4.7)$ \\
\hline Obesity $(\mathrm{BMI} \geq 30), \mathrm{N}(\%)$ & $129(15)$ & $64(23)$ & $0.001 \#$ & $193(16)$ \\
\hline Daily smoking, N (\%) & $84(9)$ & $52(18)$ & $<0.001 \#$ & $136(11)$ \\
\hline
\end{tabular}

NA: Not applicable * Non-parametric test \# Adjusted for sex 
Table 3. Univariate and multivariable logistic regression analyses of young adult cancer survivors being non-employed $(\mathrm{N}=\mathbf{2 9 2})$ and employed $(\mathrm{N}=\mathbf{8 9 7})$ as reference.

\begin{tabular}{|c|c|c|c|c|c|c|}
\hline Variables & \multicolumn{3}{|c|}{ Univariate analyses } & \multicolumn{3}{|c|}{ Multivariable analysis } \\
\hline & OR & $95 \% \mathrm{CI}$ & p-value & OR & $95 \% \mathrm{CI}$ & p-value \\
\hline Age at survey & 1.03 & $1.01-1.05$ & 0.001 & 1.01 & $0.98-1.05$ & 0.40 \\
\hline Time since diagnosis & 1.03 & $1.01-1.05$ & 0.002 & 1.05 & $1.01-1.09$ & 0.02 \\
\hline Treatment groups & - & & 0.02 & & & 0.74 \\
\hline Minimal surgery & 1.00 & - & - & 1.00 & - & \\
\hline Local treatment & 1.31 & $0.80-2.16$ & 0.29 & 0.84 & $0.46-1.53$ & \\
\hline Systemic treatment only & 1.78 & $1.09-2.90$ & 0.02 & 1.13 & $0.61-2.08$ & \\
\hline Systemic + others & 1.79 & $1.19-2.71$ & 0.005 & 0.90 & $0.52-1.56$ & \\
\hline No of adverse effects & 1.21 & $1.16-1.26$ & $<0.001$ & 1.12 & $1.04-1.21$ & 0.004 \\
\hline Females (males reference) & 1.77 & $1.28-2.46$ & 0.001 & 1.90 & $1.27-2.84$ & 0.002 \\
\hline Low basic education & 2.52 & $1.92-3.30$ & $<0.001$ & 2.11 & $1.53-2.92$ & $<0.001$ \\
\hline Comorbidities & & & & & & \\
\hline Cardiovascular diseases & 2.66 & $2.01-3.52$ & $<0.001$ & 1.85 & $1.31-2.63$ & 0.001 \\
\hline Musculoskeletal diseases & 2.04 & $1.55-2.68$ & $<0.001$ & 0.95 & $0.68-1.34$ & 0.78 \\
\hline Mental disorders & 2.18 & $1.65-2.88$ & $<0.001$ & 1.30 & $0.91-1.85$ & 0.15 \\
\hline General Health & 0.96 & $0.95-0.97$ & $<0.001$ & 0.98 & $0.97-0.98$ & $<0.001$ \\
\hline Total fatigue & 1.16 & $1.13-1.19$ & $<0.001$ & 1.04 & $0.99-1.08$ & 0.06 \\
\hline Anxiety & 1.13 & $1.10-1.17$ & $<0.001$ & $\mathrm{MC}$ & & \\
\hline Depression & 1.18 & $1.15-1.22$ & $<0.001$ & 1.06 & $1.01-1.11$ & 0.02 \\
\hline Daily smoking & 2.10 & $1.44-3.05$ & $<0.001$ & 1.22 & $0.77-1.93$ & 0.41 \\
\hline Obesity & 1.70 & $1.21-2.37$ & 0.002 & 1.14 & $0.76-1.72$ & 0.53 \\
\hline
\end{tabular}

MC: Not included in multivariate analysis due to multicollinearity with Depression. 
Table 4. Characteristics of young adult cancer survivors with high $(\mathrm{N}=706)$ and low current ( $\mathrm{N}=434)$ work ability.

\begin{tabular}{|c|c|c|c|}
\hline Variables & $\begin{array}{c}\text { High work } \\
\text { ability } \\
(\mathrm{N}=706)\end{array}$ & $\begin{array}{c}\text { Low work } \\
\text { ability } \\
(\mathrm{N}=\mathbf{4 3 4})\end{array}$ & p-value \\
\hline Age at first diagnosis, mean (SD) & $32.6(7.6)$ & $33.3(5.4)$ & $0.07 \#$ \\
\hline Age at survey, mean (SD) & $49.4(7.6)$ & $49.7(8.0)$ & $0.53 \#$ \\
\hline Time since diagnosis, mean (SD) & $16.3(6.7)$ & $15.8(6.7)$ & $0.48 \#$ \\
\hline Types of cancer, $N(\%)$ & & & $<0.001$ \\
\hline Melanomas & $157(22)$ & $33(8)$ & $<0.001$ \\
\hline Breast & $267(38)$ & $205(47)$ & 0.002 \\
\hline Colo-rectal & $94(13)$ & $46(10)$ & 0.19 \\
\hline Non-Hodgkin lymphomas & $113(16)$ & $94(22)$ & 0.018 \\
\hline Leukemias & $75(11)$ & $56(13)$ & 0.25 \\
\hline Treatment groups, $N(\%)$ & & & $<0.001$ \\
\hline Minimal surgery & $157(22)$ & $33(7)$ & $<0.001$ \\
\hline Local treatment & 135 (19) & $60(14)$ & 0.023 \\
\hline Systemic treatment only & $109(15)$ & $73(17)$ & 0.56 \\
\hline Systemic + others & $305(43)$ & $268(62)$ & $<0.001$ \\
\hline Relapse, N (\%) & $73(10)$ & $73(17)$ & 0.001 \\
\hline $\begin{array}{l}\text { Metastases ever (breast and colo- } \\
\text { rectal cancers) N (\%) }(\mathbf{N}=\mathbf{6 3 8})\end{array}$ & $196(31)$ & $143(22)$ & 0.004 \\
\hline $\begin{array}{l}\text { Number of cancers, } N(\%) \\
\text { One cancer only } \\
\text { Two or more cancers }\end{array}$ & $\begin{array}{c}664(94) \\
42(6)\end{array}$ & $\begin{array}{l}387(89) \\
47(11)\end{array}$ & 0.003 \\
\hline $\begin{array}{l}\text { Number of late adverse effects, } \\
\text { mean (SD) }\end{array}$ & $1.5(1.9)$ & $3.1(2.5)$ & $<0.001 * \#$ \\
\hline $\operatorname{Sex}, N(\%)$ & & & 0.001 \\
\hline
\end{tabular}




\begin{tabular}{|c|c|c|c|}
\hline Females & $487(69)$ & $339(78)$ & \\
\hline Males & 219 & $95(22)$ & \\
\hline In paired relationship, $\mathrm{N}(\%)$ & $556(78)$ & $330(76)$ & 0.28 \\
\hline Level of basic education, $N(\%)$ & & & $<\mathbf{0 . 0 0 1 \#}$ \\
\hline $\operatorname{High}(>12$ years $)$ & $464(66)$ & $213(49)$ & \\
\hline Low $(\leq 12$ years $)$ & 241 & $221(51)$ & \\
\hline Work status, $N(\%)$ & & & $<0.001$ \\
\hline Full time job & $583(83)$ & $104(24)$ & $<0.001$ \\
\hline Part time job & $81(11)$ & $100(23)$ & $<0.001$ \\
\hline On sick leave & $5(1)$ & $19(4)$ & $<0.001$ \\
\hline Disability pension & $6(1)$ & $153(35)$ & $<0.001$ \\
\hline Work assessment allowance & $2(0)$ & $37(9)$ & $<0.001$ \\
\hline Other statuses & $28(4)$ & $22(5)$ & 0.38 \\
\hline Work ability index, mean (SD) & $9.1(0.9)$ & $4.5(2.3)$ & $<0.001 \#$ \\
\hline \multicolumn{4}{|l|}{ Comorbidity, $N(\%)$} \\
\hline Cardiovascular diseases & $151(21)$ & $150(35)$ & $<0.001 \#$ \\
\hline Musculo-skeletal diseases & $307(44)$ & $285(67)$ & $<0.001 \#$ \\
\hline Mental disorders & $142(20)$ & $171(39)$ & $<0.001 \#$ \\
\hline General health, mean (SD) & $83.1(17.2)$ & $56.1(22.7)$ & $<0.001 \#$ \\
\hline Total fatigue, mean (SD) & $11.2(3.4)$ & $16.4(5.6)$ & $<0.001 \#$ \\
\hline Anxiety, mean (SD) & $3.7(3.1)$ & $6.2(4.1)$ & $<0.001 * \#$ \\
\hline Depression, mean (SD) & $3.5(3.3)$ & $8.3(5.1)$ & $<0.001 * \#$ \\
\hline Obesity $(\mathrm{BMI} \geq 30), \mathrm{N}(\%)$ & $97(14)$ & $87(21)$ & 0.003\# \\
\hline Daily smoking, N (\%) & $62(9)$ & $63(15)$ & $0.006 \#$ \\
\hline
\end{tabular}

NA: Not applicable * Non-parametric test \# Adjusted for sex 
Table 5. Univariate and multivariable logistic regression analyses of young adult cancer survivors low $(\mathrm{N}=434)$ and high current work ability $(\mathrm{N}=706)$ as reference.

\begin{tabular}{|c|c|c|c|c|c|c|}
\hline \multirow[t]{2}{*}{ Variables } & \multicolumn{3}{|c|}{ Univariate analyses } & \multicolumn{3}{|c|}{ Multivariable analysis } \\
\hline & OR & $95 \% C I$ & $\boldsymbol{P}$ & OR & $95 \% \mathrm{CI}$ & $\boldsymbol{P}$ \\
\hline Age at first diagnosis & 1.03 & $1.00-1.05$ & 0.02 & 1.02 & $0.99-1.06$ & 0.14 \\
\hline Treatment groups & & & & & & 0.06 \\
\hline Minimal surgery & 1.00 & - & - & 1.0 & - & - \\
\hline Local treatment & 2.11 & $1.30-3.43$ & 0.002 & 1.31 & $0.69-2.47$ & 0.41 \\
\hline Systemic treatment only & 3.19 & $1.98-5.14$ & $<0.001$ & 2.07 & $1.08-3.95$ & 0.03 \\
\hline Systemic + others & 4.18 & $2.78-6.30$ & $<0.001$ & 1.98 & $1.11-3.52$ & 0.02 \\
\hline No of adverse effects & 1.37 & $1.30-1.45$ & $<0.001$ & 1.13 & $1.04-1.23$ & 0.003 \\
\hline Females (males reference) & 1.61 & $1.22-2.12$ & 0.001 & 1.23 & $0.82-1.84$ & 0.31 \\
\hline Low basic education & 2.00 & $1.57-2.55$ & $<0.001$ & 1.87 & $1.34-2.61$ & $<0.001$ \\
\hline Comorbidities & & & & & & \\
\hline Cardiovascular diseases & 1.94 & $1.49-2.54$ & $<0.001$ & 1.52 & $1.05-2.20$ & 0.025 \\
\hline Musculoskeletal diseases & 2.49 & $1.94-3.18$ & $<0.001$ & 1.20 & $0.85-1.68$ & 0.30 \\
\hline Mental disorders & 2.58 & $1.98-3.37$ & $<0.001$ & 1.20 & $0.83-1.75$ & 0.33 \\
\hline General health & 0.94 & $0.93-0.95$ & $<0.001$ & 0.96 & $0.95-0.97$ & $<0.001$ \\
\hline Total fatigue & 1.32 & $1.27-1.37$ & $<0.001$ & 1.13 & $1.08-1.18$ & $<0.001$ \\
\hline Anxiety & 1.21 & $1.17-1.26$ & $<0.001$ & $\mathrm{MC}^{1}$ & & \\
\hline Depression & 1.33 & $1.20-1.38$ & $<0.001$ & 1.10 & $1.04-1.15$ & $<0.001$ \\
\hline Obesity & 1.59 & $1.16-2.19$ & 0.004 & 1.06 & $0.69-1.63$ & 0.78 \\
\hline Daily smoking & 1.76 & $1.21 .-2.56$ & 0.003 & 0.87 & $0.52-1.45$ & 0.59 \\
\hline
\end{tabular}

$\mathrm{MC}^{1}$ : Not included in multivariate analysis due to multicollinearity with PHQ Depression. 